\title{
Electroconvulsive therapy, capacity and the law in Ireland
}

\author{
Ross Dunne, Adam Kavanagh, Declan M McLoughlin
}

Ir J Psych Med 2009; 26(1): 3-5

\begin{abstract}
The Mental Health Act (MHA) 2001 has major implications for treating patients with electroconvulsive therapy (ECT), especially as those referred for treatment are among the most severely ill and often lose capacity. Under the MHA 2001, a person may only be treated without consent if they are an involuntary patient. However, there is no provision in the Act for treating voluntary inpatients whose mental state has deteriorated but who do not seek to leave hospital. Such people may lack capacity to make treatment decisions but be passively compliant.

The Wards of Court system is currently the only legal recourse but has been criticised by the Law Reform Commission and is unwieldy. Further legislation governing treatment of people lacking capacity to consent to ECT or withhold consent is required to protect and advance treatment of all concerned.
\end{abstract}

Key words: Electroconvulsive therapy; Informed consent; Commitment of mentally ill; Mental competency.

In November 2006 the Mental Health Act (MHA) 2001 replaced both the Mental Treatment Act 1945 and associated acts and amendments from subsequent years. The Act has major implications for prescription and administration of electroconvulsive therapy (ECT), which is the most effective treatment available for severe treatment resistant depression. ${ }^{1}$ As such, ECT is often given to severely ill patients with a related loss of decision-making capacity. ${ }^{2}$ Impaired capacity is often associated with severe mental illness. In one study $60 \%$ of psychiatric inpatients lacked capacity to make treatment decisions, with rates varying from $4 \%$ in those with a diagnosis of personality disorder to $97 \%$ in people with mania. $^{3}$

The Act states that a person may only be treated against their will if they are an involuntary patient. When making an admission order, a consultant psychiatrist must assess whether a person is suffering from 'mental disorder', is a danger to themselves or others, or whether the person requires admission for treatment. ${ }^{4}$ However, the MHA 2001

${ }^{*}$ Ross Dunne, MB, Research Registrar, Department of Psychiatry, Trinity College Dublin, St Patrick's Hospital, Dublin 8, Ireland. Email: ross.dunne@tcd.ie

Adam Kavanagh, RPN MSc, Research Nurse,

Declan M McLoughlin, PhD MRCPI MRCPsych, Research Professor of Psychiatry, Department of Psychiatry and Trinity College Institute of Neuroscience, Trinity College Dublin, St. Patrick's Hospital, Dublin 8, Ireland.

${ }^{*}$ Correspondence

SUBMITTED: SEPTEMBER 24, 2008. ACCEPTED: JANUARY 21, 2009 does not address the issue of capacity. We will address this as it pertains to ECT and the law in Ireland, as this is currently a major deficiency in Irish legislation.

\section{Capacity}

Documenting capacity includes assessing the ability to communicate a choice, to understand relevant information, to appreciate the consequences of a decision and to reason about treatment choices. ${ }^{5}$ Standards for assessing capacity vary. For example, mental capacity should not be assessed using a status approach or an outcomes approach. The status approach assumes that between two points in time a person's decision making capacity does not change. During this time, a range of treatments can be used without re-assessment. It may be based on diagnosis and takes no account of specific domains within which a person may be fully able to understand and weigh decisions. The outcomes approach depends upon the subjective assessment of likely outcomes and their accordance with the patient's best interests, which is necessarily culture-bound and might lead to paternalism on the part of doctors. ${ }^{6}$ It is more appropriate to use a functional approach, in which capacity is evaluated with regard to each decision. This issue-specific approach takes into consideration an individual's capacity at the time the decision is made.

We wish to underline the importance of capacity as there has been a trend to view the involuntary patient as de facto incapacitated. This is unacceptable. Equally, it is no longer tenable to assume that a patient is incapacitated with regard to a particular treatment decision when their decision is at odds with international best practice or their treating doctor's advice. ${ }^{7}$

The lack of legislation in Ireland directly addressing the issue of capacity has implications for ECT treatment. This often life-saving treatment might be denied to voluntary patients who become progressively more unwell and lose the capacity to make major decisions relevant to their care. The 'Rules for $\mathrm{ECT}^{\prime 8}$ state that involuntary patients with capacity who agree to the treatment may be treated without a second opinion. However, patients who are unwilling to consent to ECT may be treated after a second opinion regardless of their mental capacity.

For a voluntary inpatient to be detained under Section 24 they must first indicate a wish to leave the hospital (Section 23). Although stated in the MHA 2001, this has also been confirmed by judicial decision. ${ }^{9}$ There is no provision in the MHA 2001 for treatment of people who sought their own admission but subsequently lose the capacity to decide on a treatment process. For example, a patient may voluntarily admit themselves to hospital suffering from a depressive episode, engage with treatment but deteriorate clinically. 


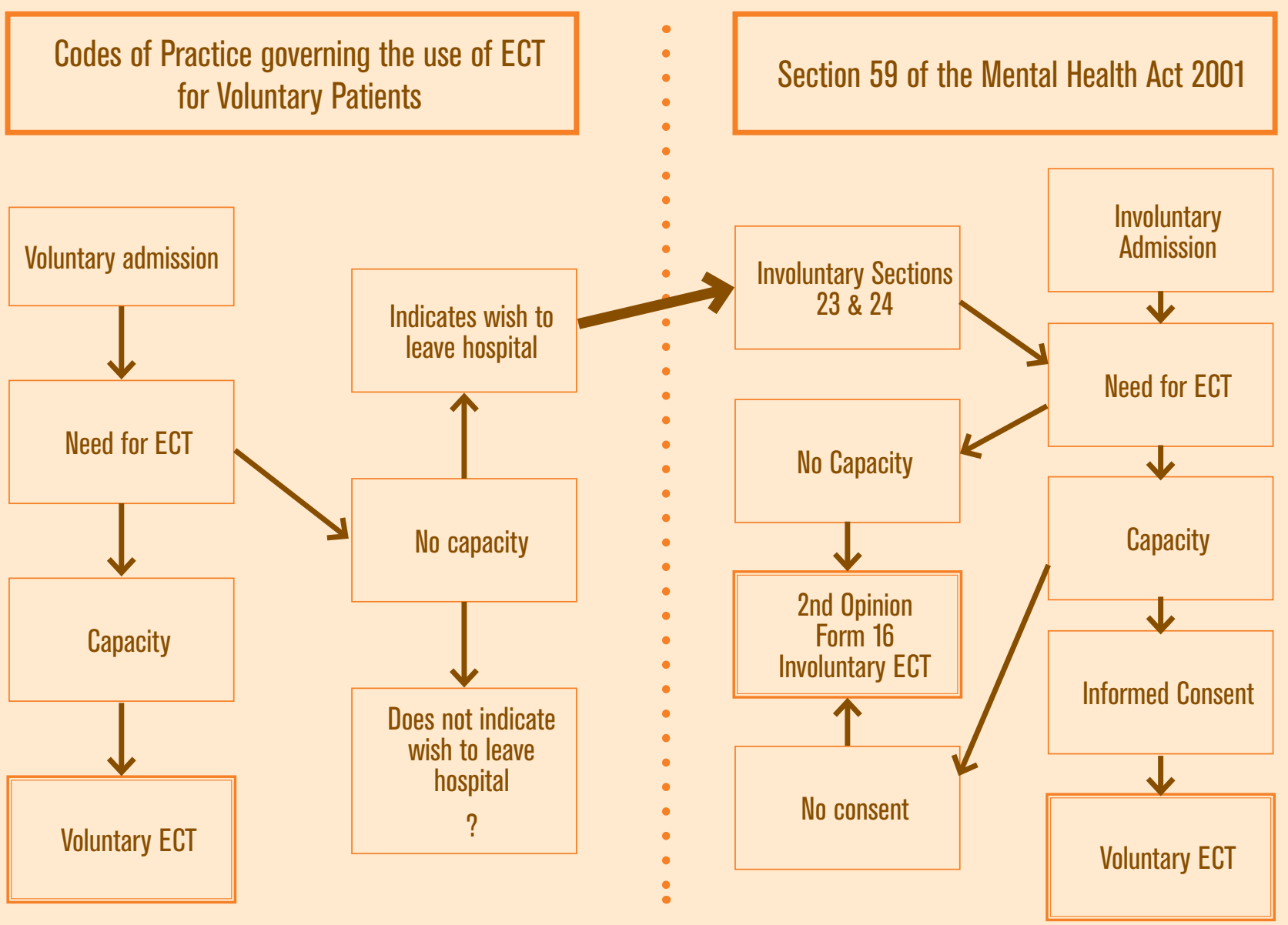

Such a patient might become stuporose but be passively compliant with medication. The patient might benefit from $\mathrm{ECT}$, but there is currently no way to treat them within the law. One possibility is to discharge and re-admit patients. We find this to be neither in the spirit of the Act nor in the best interests of the patient. It would constitute an 'involuntary discharge' in a patient incapable of consenting to discharge. This violates the treatment contract. Another possibility is to subvert the Act by having an application made to admit the person involuntarily as if they were an outpatient, even though they are voluntary inpatients. This solution is legally precarious at best. The Mental Health Commission (MHC) does not support such practice.

The MHC acknowledges that the Act makes no provision for the assessment of capacity, although the 'Rules for ECT' do outline the assessment of capacity and informed consent. ${ }^{10,11}$ The most recent 'Code of practice governing the use of ECT for voluntary patients (2008)' is also silent on this issue. ${ }^{12}$

The current pathways to ECT treatment are outlined in Figure 1, which illustrates that clarification is needed with regard to voluntary, but incapacitated, patients and also for detained patients with capacity to refuse ECT. We must have legal procedures that safeguard patients' best interests and provide for common eventualities without the need for the traditional 'Irish solution to an Irish problem' approach. A system is required where best medical practice and best legal practice are not mutually exclusive.

\section{The Mental Capacity and Guardianship Bill 2007}

The Law Reform Commission (LRC) published the consultation paper Mental Capacity and Vulnerable Adults in 2005 coinciding with the enactment of the Mental Capacity Act in the United Kingdom. ${ }^{13}$ This was followed in 2006 by publication of their final report ${ }^{14}$ with proposals similar to those currently in force in the UK. The assessment of capacity is deemed to be a distinct issue, and one which applies to a far greater variety of situations than those envisaged in the MHA 2001 , including the capacity of patients to consent to surgical procedures, testamentary capacity and enduring power of attorney.

The LRC recommendations culminated in the Mental Capacity and Guardianship Bill 2007, which passed through the second stage in the Seanad in February 2007 and has now been passed to the committee stage..$^{15}$ The Bill replaces the Wards of Court system with a Guardianship system, whereby a voluntary but incapacitated patient would have a public guardian appointed to make healthcare decisions for them. The Bill states that the known views of the patient and the wishes of their family should be taken into account; however, it is not clear whether family members can make decisions on behalf of a relative. It is notable that ECT is not explicitly mentioned in the Bill but this legislation would form the pathway to care for incapacitated passively compliant patients when ECT is indicated.

It is unclear how the proposed guardianship legislation will work in practice and how it will change the treatment of 
voluntary but incapacitated patients who would benefit from ECT. It is conceivable that these patients would have a public guardian appointed before treatment with ECT. However, the Bill states that some decisions can be taken in the best interests of the patient where they lack capacity. For example, pending a decision from a guardianship board, the treating team is bound to prevent deterioration in the patient's condition.

The Bill also states that a Public Guardian may not refuse consent to the "carrying out or continuation of life-sustaining treatment". What constitutes life-sustaining treatment is not made explicit, but Section 27 of the Bill instructs the Office of the Public Guardian to construct codes of practice concerning the implementation of the Act.

Capacity is defined in the Bill as "the ability to understand the nature and consequences of a decision in the context of available choices at the time the decision is to be made". As no test for capacity is mentioned in the current stage of the Bill, it will be incumbent on the Office of the Public Guardian to clarify this. We fear that leaving the actual implementation of the Act to evolution, rather than appropriate planning and consultation, will result in the same problems currently encountered with the Mental Health Act 2001.

\section{Banning involuntary ECT}

In June 2008, a Private Member's Bill was debated in the Seanad. ${ }^{17}$ This Bill proposed to amend the MHA 2001 to remove Section 58 and amend Section 59, thus prohibiting the prescription of ECT for involuntary inpatients who do not consent.

Essentially, informed consent would be necessary for the prescription of ECT for involuntary patients. The aim of this proposal is to promote the use of advance directives made by patients early in the course of their illness when they have capacity. The assumption is that advance directives will prevent paternalism and promote the rights of the patient. However, no pathway to treatment is proposed for those patients who enter hospital as incapacitated patients, no alternatives are proposed in the absence of an advance directive and these are not currently recognised in Irish law. In contrast, the scientific evidence brought to the debate by the Minister for State highlighted that the state has a duty of care to involuntary patients which would be potentially undermined by a ban on involuntary ECT.

A ban on involuntary ECT would render us unable to treat some of the most mentally ill patients in society. It would lead to medical deterioration and subsequent general hospital treatment for some. It would mean a basic violation of the treatment contract, because our detention in hospital of involuntary patients should be based on the principle of reciprocity under which we must aim to restore decision-making capacity to incapacitated patients.

Inevitably, this situation has come about because of the public perception of ECT as a high-risk, low-benefit procedure; meaning that a very high threshold is set for incapacity with regard to its use. In fact ECT is one of the most effective and safe treatments in medicine. ${ }^{1}$

Currently, every medical practitioner is in a legal vacuum when caring for voluntary inpatients requiring treatment with ECT but lacking capacity. (Indeed, this applies to other treatments as well). The Mental Health Act 2001 has significantly improved the treatment process available to people suffering mental ill health in Ireland in that the addition of tribunals and the checks and balances on involuntary admission aim to protect patients' rights and interests. The proposed Mental Capacity and Guardianship Bill will secure the presumption of capacity in Irish law. However, it remains to be seen how the yet to be developed 'codes of practice' will impact upon the treatment of voluntary but incapacitated patients with ECT.

\section{Acknowledgements}

Our work is supported by the Health Research Board and the Friends of St Patrick's Hospital.

\section{Declarations of interest: None.}

\footnotetext{
References

1. UK ECT Review Group. Efficacy and safety of electroconvulsive therapy in depressive disorders: a systematic review and meta-analysis. Lancet 2003 Mar 8; 361(9360): 799-808.

2. Hotopf M, Laird B, Singh I et al. Capacity, consent and electroconvulsive therapy: A qualitative and cross-sectional study. J Mental Health 2008; 17(3): 315-325.

3. Owen GS, Richardson G, David AS, Szmukler G, Hayward P, Hotopf M. Mental capacity to make decisions on treatment in people admitted to psychiatric hospitals: cross sectional study. BMJ 2008; 337: a448.

4. Oireachtas na hÉireann, Mental Health Act, 2001, Part 1, Section 3, Subsection 1 , (a) \& (b). www.irishstatutebook.ie/2001/en/act/pub/0025/index.html

(a) \& (b). www.irishstatutebook.ie/2001/en/act/pub/0025/index.html 5. Appelbaum PS. Assessment of patients' competence to consent to treatment. New Eng J Med 2007 Nov 1; 357(18): 1834-40.

6. Law Reform Commission, Report - Vulnerable Adults and the Law, (83-2006) December 2006. Section 1.63. www.lawreform.ie/Vulnerable $\% 20$ Adults $\% 20$ Report\%20Final\%20Dec\%202006.pdf

7. Grisso T, Applebaum PS. Assessing competence to consent to treatment - A guide for physicians and other health professionals. Oxford University Press: New York, for physic 1998 .

1998. Reference Number: R-S59(2)/01/2006 www.mhcirl.ie/act/Rules\%20for\%20the\%20 use $\% 20$ of $\% 20 \% 20$ Electroconvulsive $\% 20$ Therapy $\% 20$ MHA\%202001\%20S59(2).pdf 9. Decision of Mr Justice Higgins, 21st December 2006: Q vs. St. Patrick's Hospital (respondent) and MHT, MHC (Notice Parties).

10. Communication from Mental Health Commission to Dr Ross Dunne specifically 10. Communication
regarding this issue.

11. Oireachtas na hÉireann, Mental Health Act, 2001, Part 4, Section 56, (a) \& (b).

12. Mental Health Commission, Code of Practice Governing the Use of ElectroConvulsive Therapy for voluntary patients. Reference Number: COP-S33/02/2008 www.mhcirl.ie/act/COP\%20-\%20S33-02-2008\%20Use\%20of\%20ECT\%20for\%20 Voluntary\% 20Patients.pdf

13. United Kingdom, Parliament. Mental Capacity Act 2005. www.dca.gov.uk/menincap/ 13. United Kingdom, Parliament. Mental Capacity Act 2005. www.dca.gov.uk/menincap/
legis.htm

14. Law Reform Commission, Report - Vulnerable Adults and the Law, (83-2006) December 2006

15. Seanad Éireann, Mental Capacity and Guardianship Bill 2007. www.oireachtas.ie/ documents/bills28/bills/2007/1207/b1207s.pdf

16. Ibid. Section 27, (1), (d).

17. Seanad Éireann, Mental Health (Involuntary Procedures) (Amendment) Bill 2008 http://www.oireachtas.ie/documents/bills28/bills/2008/3608/b3608s.pdf
}

\section{Cover series 2009}

This year we continue our cover series of artwork from the artists involved in the art therapy group at the Central Mental

Hospital, Dundrum, Co Dublin, Ireland. Art, as a therapeutic activity for patients, began in the 1970s at the hospital and became part of the vocational education programme there in 1985. Patients' work has been exhibited in a number of initiatives including the Lundbeck Art Initiative and in various venues throughout the country including

$$
\text { Cork, Kilkenny, Dublin and Wicklow. }
$$

